\title{
Primary Anterior Cruciate Ligament Reconstruction. How Do We Do It?
}

\author{
Adrian Todor', Vlad Predescu², Bogdan Codorean², Radu Prejbeanu ${ }^{3}$, Mihai Roman, Radu \\ Fleaca ${ }^{4}$, Octav Russu ${ }^{5}$, Tiberiu Bățagă5 \\ 1 “Iuliu Hațieganu” University of Medicine and Pharmacy, Cluj-Napoca, Romania \\ 2 "Carol Davila" University of Medicine and Pharmacy, Bucharest, Romania \\ 3 "Victor Babeș" University of Medicine and Pharmacy, Timișoara, Romania \\ 4 "Victor Papillan" Faculty of Medicine, "Lucian Blaga” University, Sibiu, Romania \\ 5 University of Medicine and Pharmacy, Tîrgu Mureș, Romania
}

\section{CORRESPONDENCE}

\section{Mihai Roman}

Str. Lucian Blaga nr. 2A

550169 Sibiu, Romania

Tel: +40 269212320

E-mail: mihaidanroman@yahoo.com

Adrian Todor • Str. Emil Isac nr. 13, 400023 Cluj Napoca, Romania. Tel: +40 264406 843, E-mail: adi.todor@yahoo.com

Vlad Predescu • B-dul Eroii Sanitari nr. 8, 050474 București, Romania. Tel: +40 213180 719, E-mail: vladpredescu001@gmail.com

Bogdan Codorean • B-dul Eroii Sanitari nr. 8, 050474 București, Romania. Tel: +40 213180 719, E-mail: dr.codorean@traumatologie-sportiva.ro

Radu Prejbeanu • P-ța Eftimie Murgu nr. 2, 30004 Timisoara, Romania. Tel: +40 256204 400, E-mail: raduprejbeanu@gmail.com

Radu Fleaca • Str. Lucian Blaga nr. 2A, 550169 Sibiu, Romania. Tel: +40 269212 320, E-mail: rfleaca@ yahoo.com

Octav Russu • Str. Gheorghe Marinescu nr. 38 , 540139 Tîrgu Mureș, Romania. Tel: +40 265215 551, E-mail: octav@genunchi.ro

Tiberiu Bățagă • Str. Gheorghe Marinescu nr. 38 540139 Tîrgu Mureș, Romania. Tel: +40 265215551

E-mail: tbataga@gmail.com

\begin{abstract}
Anterior cruciate ligament $(\mathrm{ACL})$ tears are frequently seen in current practice mostly affecting the young, active subjects, and usually require ligament reconstruction in order to restore normal knee kinematics. As worldwide interest in anatomic reconstruction grew over the last decade, we have also refined our technique in order to restore the anatomical function as near to the normal as possible. This anatomical restoration concept is believed to prevent the onset of osteoarthritis, which the non-anatomic reconstructions fail to attain. The knowledge gained from the $\mathrm{ACL}$ anatomy, function and kinematics has helped in developing the current anatomic methods of reconstruction, which take into account patient anatomy, the rupture pattern, as well as the comorbidities. We present our approach to anatomical single- and double-bundle $\mathrm{ACL}$ reconstruction.
\end{abstract}

Keywords: ACL reconstruction, anatomy, single-bundle, double-bundle

\section{INTRODUCTION}

Anterior cruciate ligament (ACL) restoration represents one of the most frequently carried out surgical interventions in orthopedic sports medicine. The annual incidence of the ACL damage varies between 100,000-200,000 in the United States of America. ${ }^{1,2}$ After an ACL tear, ligament reconstruction is commonly accepted as the most consistent technique for restoring knee stability. ${ }^{3}$ The principles of ACL restoration are to reestablish knee steadiness and normal knee kinematics after surgery, in other words, to bring back the patient to the previous level of activity while preventing degenerative changes in the knee. ${ }^{4}$ More so, individualized ACL restoration has been described tailored to patient anatomy (insertion site size, notch size, and shape). ${ }^{5}$ Thus, anatomical ACL reconstruction is defined as restoring the ACL to its native size, collagen orientation, and insertion sites. ${ }^{6}$ 
The ACL contains two different functional bundles: the anteromedial (AM) and the posterolateral (PL) bundle, named by their insertion site located on the tibia. ${ }^{7,8}$ Even if single-bundle (SB) ACL restoration is currently the standard procedure, the double-bundle (DB) anatomy knowledge has led to improvement in the SB reconstruction technique, and to the development of the anatomic $\mathrm{SB}$ concept that places the tunnels in the center of the ACL femoral and tibia imprints. ${ }^{2}$

The purpose of this article is to describe the technique that we use in our department for primary ACL reconstruction, single- and double-bundle.

\section{CONCEPT}

We follow the individualized anatomic ACL reconstruction concept. ${ }^{3,4,9}$ The first phase is to perform preoperative assessment of the patient's ACL anatomy with the help of magnetic resonance imaging (MRI). On the sagittal sequence the imprints are measured as shown in Figure 1. If the imprints are smaller than $16 \mathrm{~mm}$ a SB technique is more appropriate, and if the footprints are larger, a DB technique can be performed.

\section{GRAFT OPTIONS}

Anatomic ACL restoration can be achieved with various autografts. The most utilized autografts are the bone-patellar tendon-bone and hamstring tendons. Lately, there has been an increased attention on the quadriceps tendon autologous graft option for ACL restoration. ${ }^{10}$ Among the proposed advantages there are low morbidity at the harvest site, predictable size and great versatility, being able to be harvested in various widths, thicknesses, and lengths. ${ }^{11-15}$

\section{SURGICAL TECHNIQUE}

Routine knee arthroscopy setup is prepared. The patient undergoes general or spinal anesthesia, and is placed supinely with the knee joint bent at a $90^{\circ}$ angle, with a side post at the level of the proximal thigh and foot support. We routinely use a non-sterile thigh tourniquet, which is inflated to $300 \mathrm{mmHg}$. The leg is prepared in the ordinary setting used for knee arthroscopy.

We routinely use a three portal method with a high anterolateral one for viewing, a central portal used for viewing the femoral insertion site, and an anteromedial one for instrumentation ${ }^{16}$ (Figure 2). First, the anterolateral portal is established, the arthroscope is introduced, and the joint is inspected. Then the central portal is established using a needle for accurate placement. This portal is in the center of the tibial footprint. Last, the anteromedial portal is established also using a needle, above the medial meniscus and at a safe distance from the medial femoral condyle to allow reaming of the femoral tunnel. The central portal has great superiority in viewing the femoral insertion site of the ACL compared to the conventional anterolateral one. This difference in visibility is shown in Figure 3.

After knee joint inspection and treatment of eventual concomitant meniscal and chondral pathology, the ACL insertion sites are evaluated and measured as follows: with the arthroscope in the anterolateral portal, the tibial footprint is evaluated and carefully debrided with the shaver to maintain the borders of the footprint. Then, using an arthroscopic ruler (Linvatec Bullseye ${ }^{\bullet}$ Native ACL Ruler)
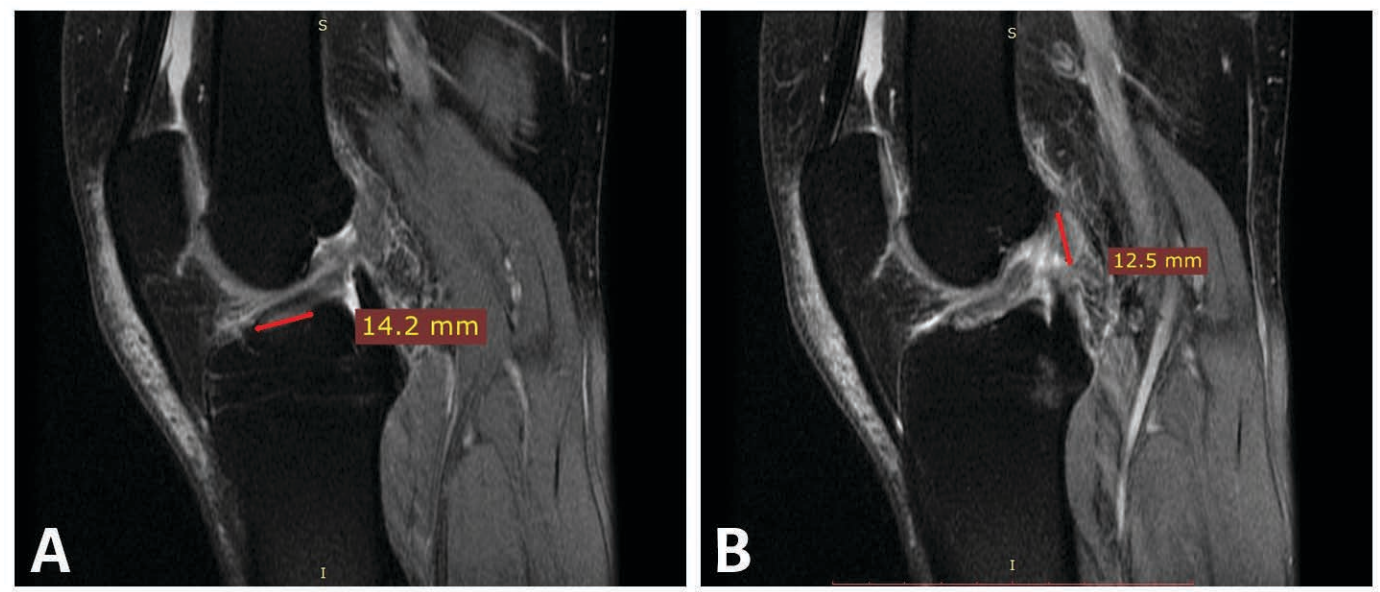

FIGURE 1. A - Tibial ACL footprint measured on the preoperative $T 2$ weighted $M R I$. B - Femoral $A C L$ footprint measured on the preoperative T2 weighted MRI 


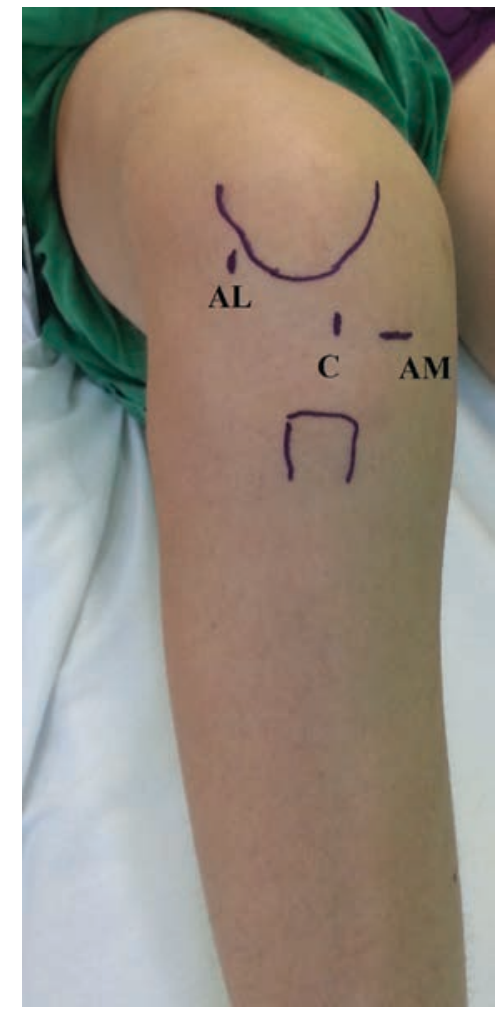

FIGURE 2. Three portals for anatomic ACL reconstruction. AL anterolateral portal, C - central portal, AM - anteromedial portal. Right knee in $90^{\circ}$ of flexion.

introduced through the central portal, the tibial insertion site dimension is measured (Figure 4). Then, the scope is inserted in the AM portal, and the femoral footprint is assessed. After careful debris removal the ruler is introduced through the $\mathrm{C}$ portal, and the femoral insertion site is measured (Figure 5). These measurements are correlated with the preoperative ones on the MRI, and they aid in the anatomical tunnel placement and decision-making over single- or double-bundle techniques.

\section{SINGLE-BUNDLE TECHNIQUE}

For single-bundle technique we set the tunnels centrally on the femoral, as well as the tibial footprints. First, the camera is introduced in the central portal, and the imprint on the lateral femoral condyle is assessed. The center of the footprint is marked with an awl (Figure 6), and the tunnel is drilled in routine fashion through the anteromedial portal. For this step the knee is bent to a $120^{\circ}$ angle of flexion. After the tunnel is created, a leading suture is inserted with the use of a guide pin. Then, the attention is redirected to the tibial side. The camera is set in the anterolateral portal, and the tibial ACL guide is placed to a $50^{\circ}$ angle, and positioned in the center of the imprint (Figure 7). The guide pin is inserted, and a tunnel is created by using the routine method. Then the graft is routed and secured with the preferred method of fixation. For soft tissue grafts, we prefer suspensory fixation on the femoral surface and interference screw on the tibial area. With the use of a free quadriceps graft, the method of femoral fixation with suspensory button was previously described by us. ${ }^{15}$

\section{DOUBLE-BUNDLE TECHNIQUE}

As mentioned in the introduction, the ACL is composed by two different functional bundles: the anteromedial and the posterolateral bundled, named by their site of insertion on the tibia.5,7,8 The two bundles work synergistically during knee motion, and influence anteroposterior and

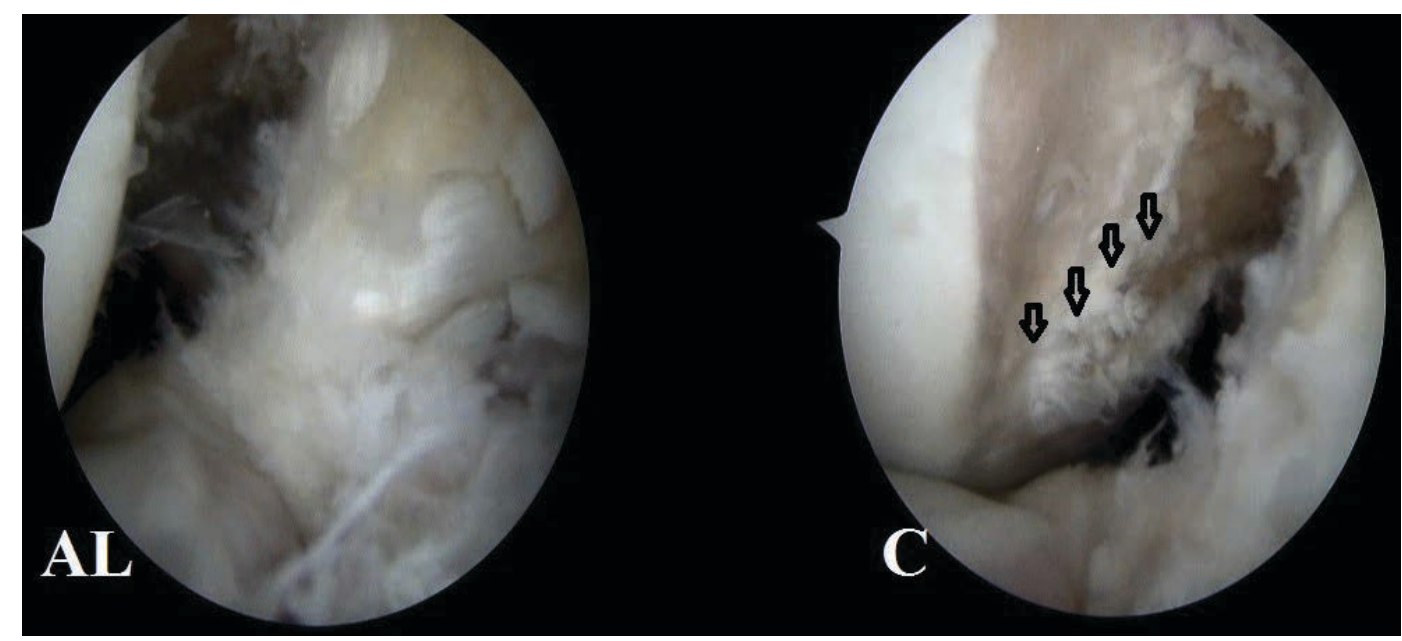

FIGURE 3. $A L-$ anterolateral viewing portal, $C$ - central viewing portal. Note the difference in visualization of the femoral $A C L$ insertion site (arrows). Right knee. 


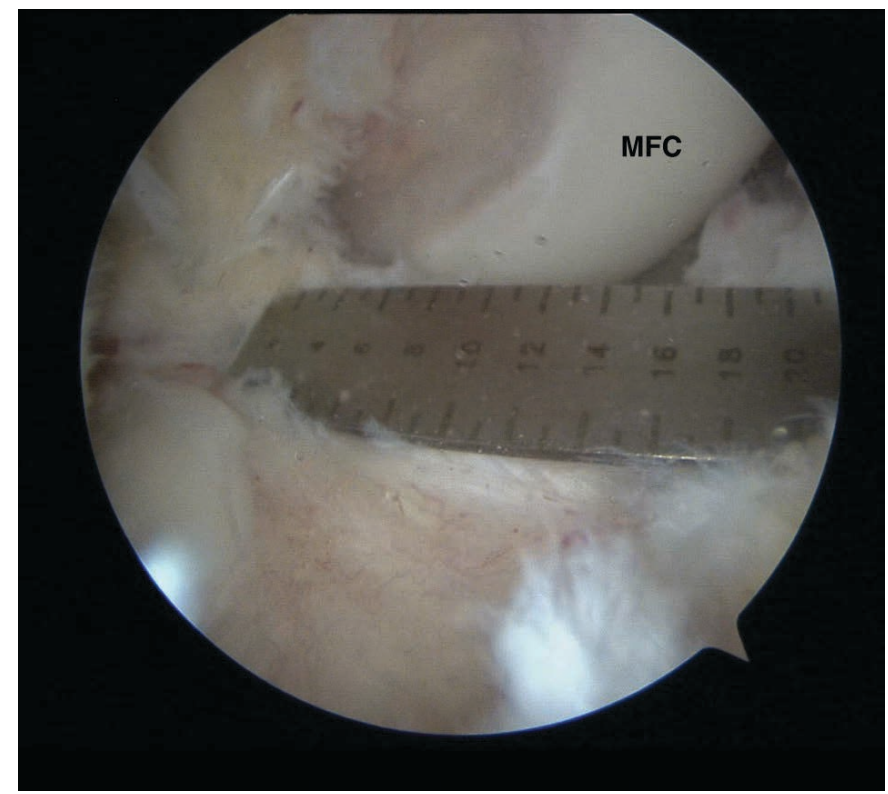

FIGURE 4. The ruler is introduced through the central portal and the tibial footprint is measured. Camera is in the anterolateral portal. Right knee. MFC - medial femoral condyle.

rotational stability. 17 The DB reconstruction aims to better reproduce the native biomechanics of the injured knee, and promote long term knee health.

The technique used by us, and presented here, uses a single femoral tunnel, two tibial tunnels and a free quadriceps tendon autograft fixed on the femur with a suspensory button and with interference screws on the tibia.

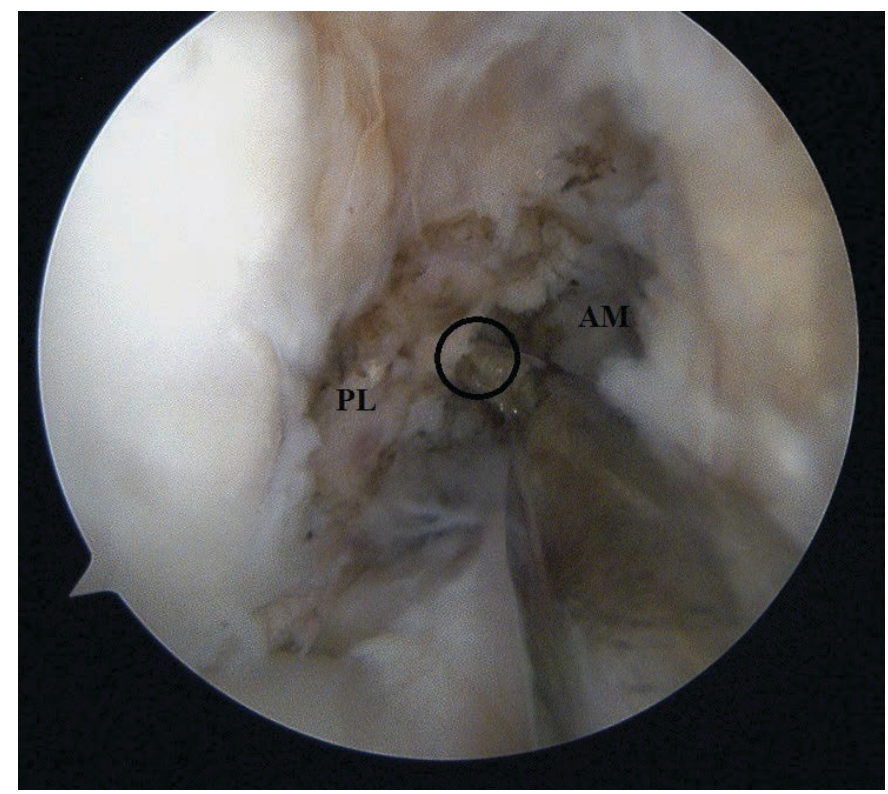

FIGURE 6. Marking of the femoral center of the $A C L$ footprint with an awl, between the posterolateral (PL) and anteromedial (AM) bundles for femoral tunnel starting point. Camera in the central portal. Right knee.

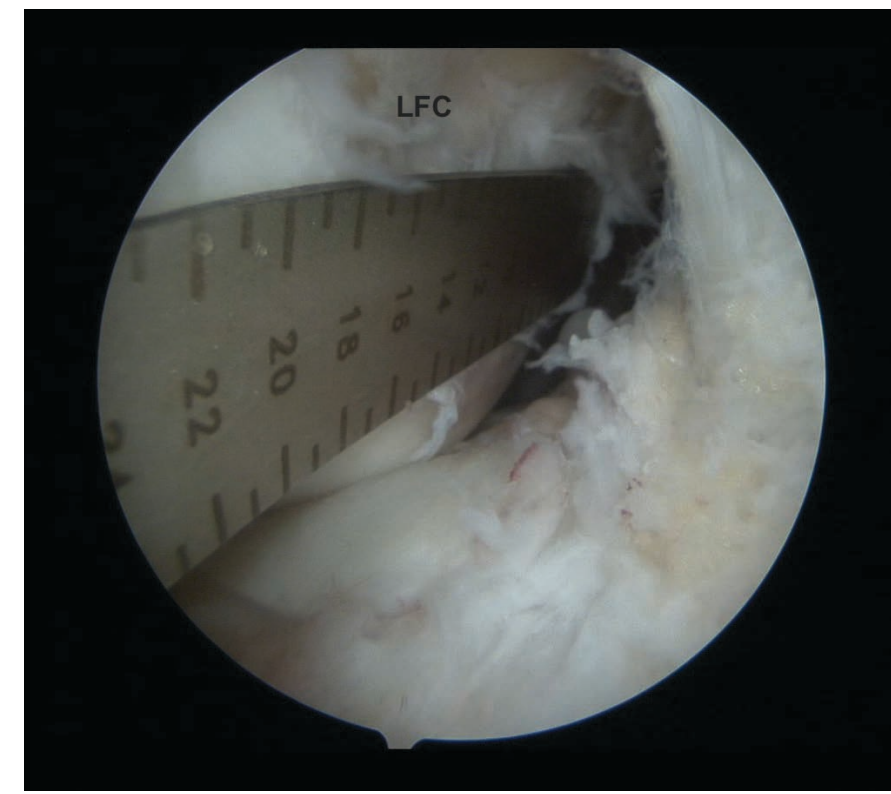

FIGURE 5. The ruler is introduced through the central portal and the femoral footprint is measured. Camera in the anteromedial portal. Right knee. LFC - lateral femoral condyle.

The patient setup and arthroscopic portals are the same as described for the SB technique. Also, the single femoral tunnel is created in the same manner as for the anatomic SB technique.

The free quadriceps graft is harvested with the knee flexed in a $90^{\circ}$ angle via a longitudinal supra patellar 3.5$4 \mathrm{~cm}$ long incision. We take a central third, $1 \mathrm{~cm}$ wide

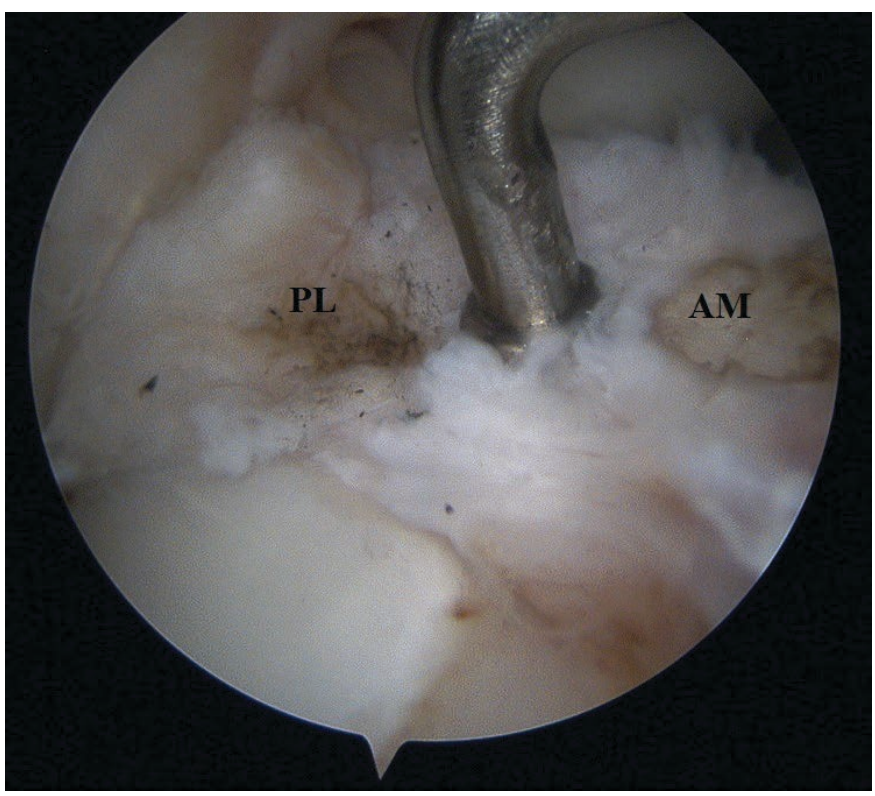

FIGURE 7. The tibial guide is introduced through the anteromedial portal in the center of the footprint, between the posterolateral $(\mathrm{PL})$ and the anteromedial (AM) bundle. Camera in the anterolateral portal. Right knee. 


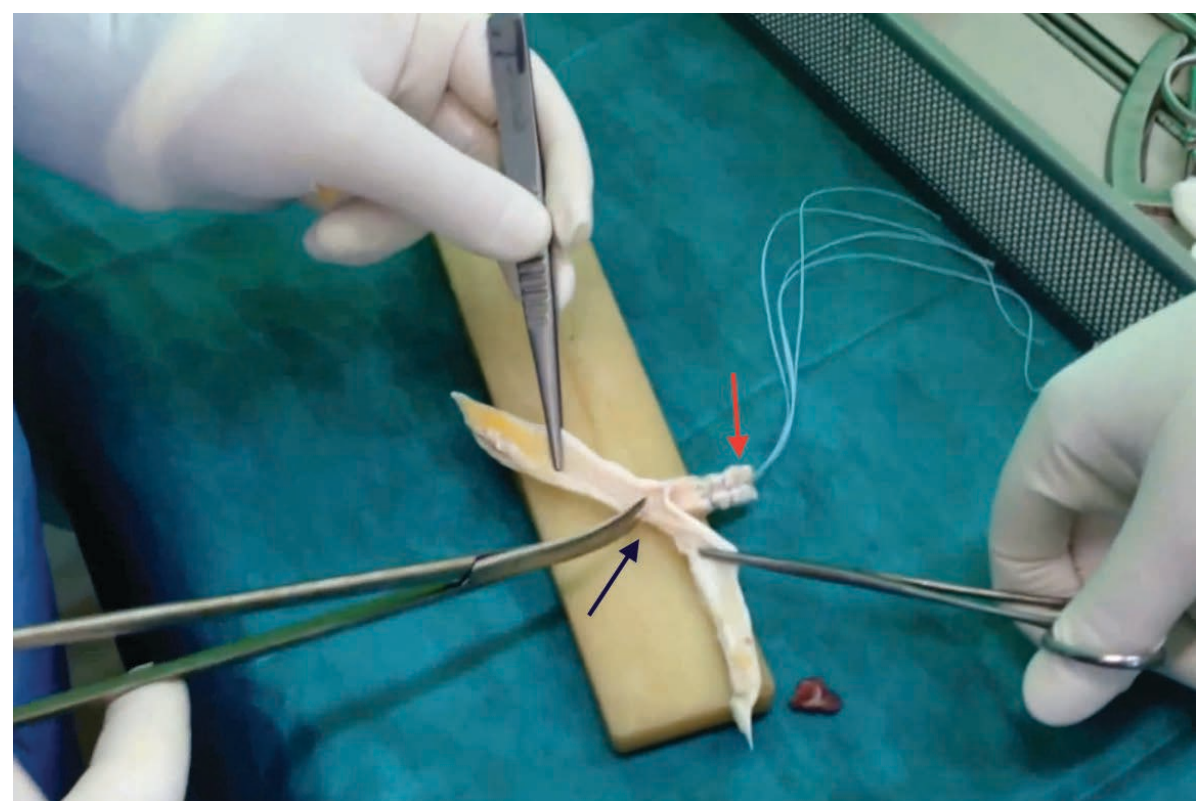

FIGURE 8. The free quadriceps tendon graft on the back table. High strength sutures are seen placed on the distal end (red arrow). The graft is split into 2 bundles with the use of scissors (black arrow) along the natural plane of cleavage between the rectus femoris and vastus intermedius providing the anteromedial and posterolateral bundles.

and 7-8 $\mathrm{mm}$ deep graft. The graft is first released from the patellar insertion, and is whip-stitched for about 2 $\mathrm{cm}$ in a standard fashion using two no. 2 high-strength polyethylene sutures. This end of the graft will be in the femoral tunnel, and the sutures used to attach the suspensory button. Any commercially available extracorti-

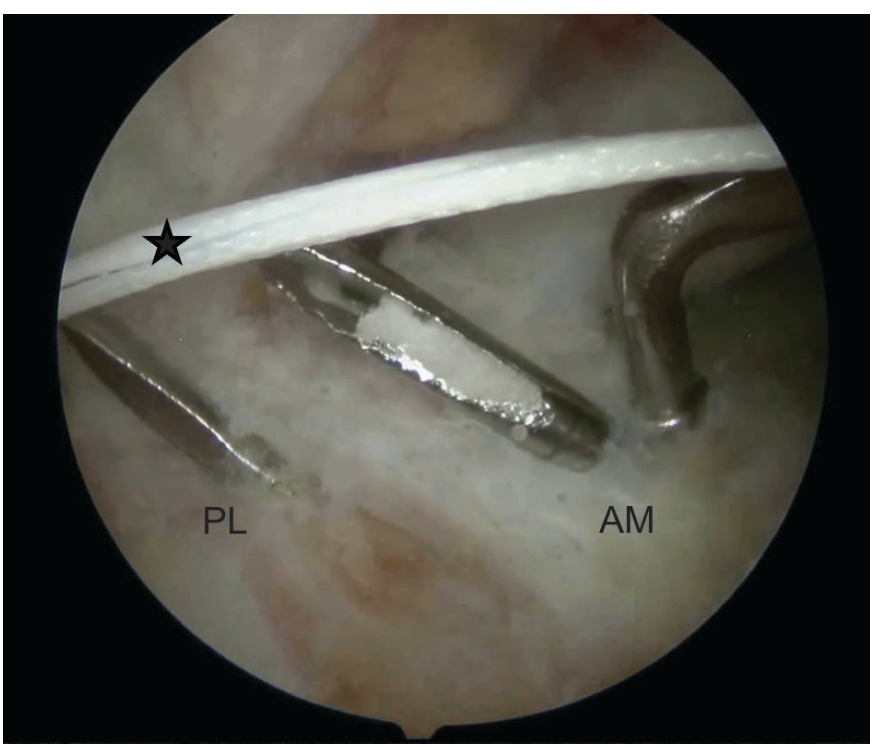

FIGURE 9. Arthroscopic view with the camera in the anterolateral portal. A guide pin is seen introduced in the PL bundle centre (PL) and another guide pin is seen in the AM bundle centre (AM). Also, the passing suture from the femoral tunnel out the AM portal can also be seen (star). Right knee. cal button with an appropriate loop dimension can be used. After the graft is harvested, it is set up for preparation.

The proximal ending of the graft is divided into two bundles using the natural plane of cleavage between the vastus intermedius and the rectus femoris (Figure 8).

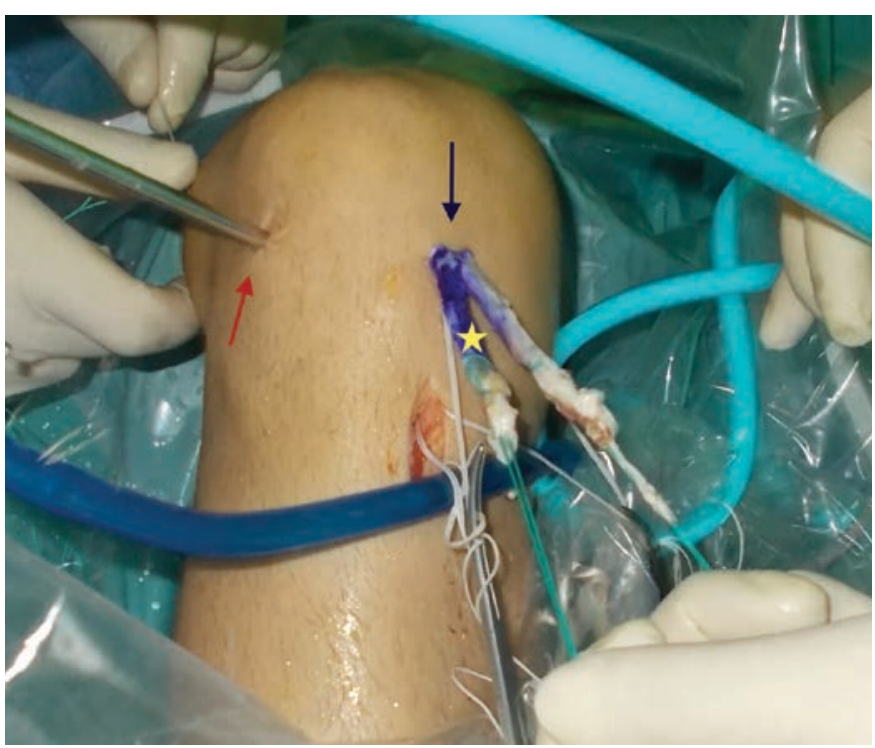

FIGURE 10. Intra operative picture during anatomic DB ACL reconstruction on a right knee. The scope is in the anterolateral portal $(\mathrm{AL})$. The black arrow indicates the PL purple passing suture secured with a clamp. The red arrow indicates the AM white passing suture also secured with a clamp. 


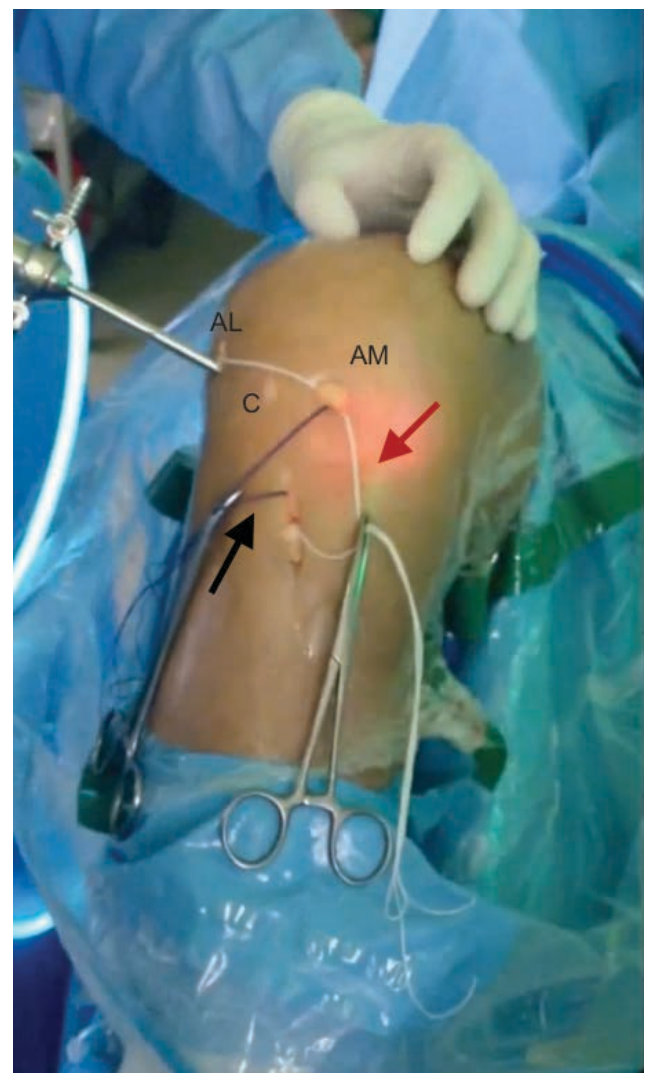

FIGURE 11. Intra-operative picture during anatomic DB ACL reconstruction on a right knee. The scope is in the anterolateral portal (red arrow). The graft is being pulled through the anteromedial portal (black arrow) with the PL bundle oriented (yellow star) such that it will enter the femoral tunnel in the correct position (shallow in the $\mathrm{ACL}$ footprint).

After the femoral tunnel is created, the scope is placed into the anterolateral portal, and the center of the PL and AM bundles on the tibia imprints are identified. A pin is introduced in the appropriate position with the ACL tibial guide set to a $45^{\circ}$ angle for the PL tunnel, and to $55^{\circ}$ for the AM tunnel (Figure 9). The tunnels are drilled with the appropriate size reamers. With the use of a graft-passing guide pin, a leading suture is introduced through the tunnels into the joint, and retrieved through the anteromedial portal for the PL and AM bundles, respectively. These sutures are each secured with a clamp. We use different color sutures for the PL and AM bundles for easier identification (Figure 10). Then, the graft is passed as follows: the sutures from the extracortical button are delivered into the joint, in the femoral tunnel and out on the lateral side of the thigh by using the leading suture placed initially. The graft is pulled through the AM portal inside the joint and in the femoral tunnel at the appropriate distance, and the button is flipped on the lateral cortex. This is confirmed by pulling on the graft. During graft insertion through the AM

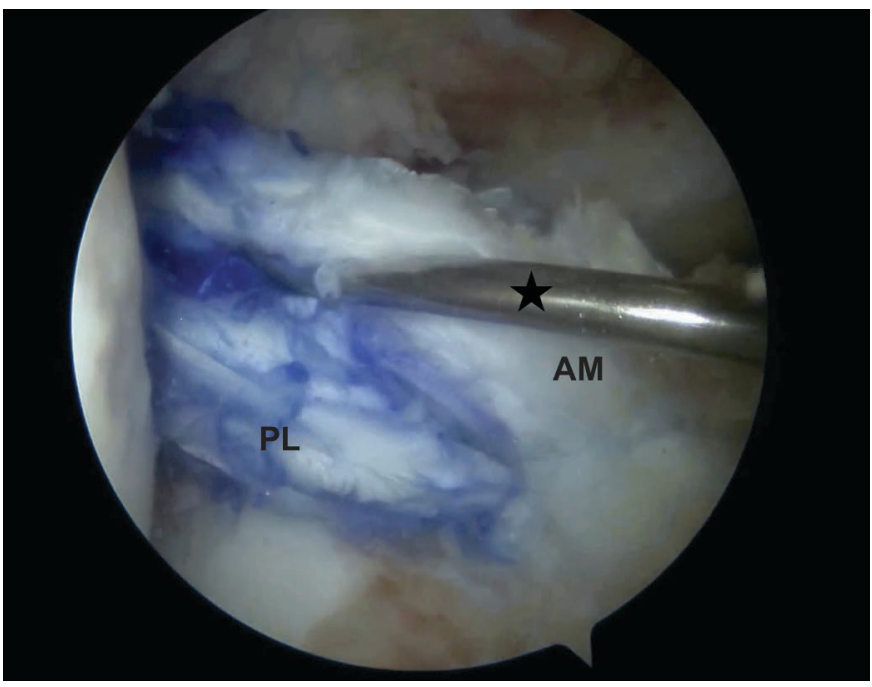

FIGURE 12. Arthroscopic view with the camera in the anterolateral portal. The quadriceps DB graft is seen in final position. The $\mathrm{PL}$ and $\mathrm{AM}$ bundles are seen in correct position. The probe (star) is introduced through the central portal.

portal, it is very important to maintain a correct orientation of the graft, so the PL bundle will enter the femoral tunnel in a superficial or anterior direction, and the AM bundle will enter in a posterior or deep position (Figure 11). Then, the suture passing through the PL tunnel will be used to pull the sutures from the PL bundle inside the joint and out the PL tunnel in the tibia, and then the bundle is pulled via the same direction. The same step is done for the AM bundle. Intraarticular examination with the placed graft is shown in Figure 12. The PL bundle is fixed with an interference screw with the knee in full extension, and the AM bundle is fixed with the knee in a $30^{\circ}$ angle of flexion.

\section{DISCUSSION}

The techniques used by us in primary ACL restoration, seek to reestablish the individual anatomical pattern of the patient, whether a SB or a $\mathrm{DB}$ reconstruction is carried out. Even if SB ACL reconstruction is still the standard procedure today, the DB anatomy knowledge has led to improvement in the SB reconstruction technique, and to the development of the anatomic SB concept that places the tunnels in the center of the ACL footprints on the femur and tibia. This anatomical placement of SB tunnels may closely reproduce native knee biomechanics. A recent clinical study showed no difference at 5 years between anatomic SB and DB reconstruction..$^{18}$ Also, a cadaveric study showed no differences in knee kinematics between the DB and SB technique with anatomical tunnels. ${ }^{19}$ An other study showed clinical superiority of the anatomic DB ACL 
reconstruction over the anatomic SB technique..$^{20}$ Even if controversy still exists in this area, it is clear that in order to restore the physiological knee biomechanics, it is of utmost importance to stick to the anatomical principles, and perform a matched ACL reconstruction tailored to the patient anatomy.

\section{CONFLICT OF INTEREST}

Nothing to declare.

\section{REFERENCES}

1. Vaishya R, Agarwal AK, Ingole S, Vijay V. Current Trends in Anterior Cruciate Ligament Reconstruction: A Review. Cureus. 2015;7:e378.

2. Kim HS, Seon JK, Jo AR. Current trends in anterior cruciate ligament reconstruction. Knee Surg Relat Res. 2013;25:165-173.

3. Hofbauer M, Muller B, Murawski CD, van Eck CF, Fu FH. The concept of individualized anatomic anterior cruciate ligament (ACL) reconstruction. Knee Surg Sports Traumatol Arthrosc. 2014;22:979-986.

4. Martins CAQ, Kropf EJ, Shen W, van Eck CF, Fu FH. The concept of anatomic anterior cruciate ligament reconstruction. Oper Tech Sports Med. 2008;16:104-115

5. Murawski CD, Wolf MR, Araki D, Muller B, Tashman S, Fu FH. Anatomic Anterior Cruciate Ligament Reconstruction: Current Concepts and Future Perspective. Cartilage. 2013;4:27S-37S

6. van Eck CF, Widhalm H, Murawski C, Fu FH. Individualized anatomic anterior cruciate ligament reconstruction. Phys Sportsmed. 2015;43:87-92.

7. Kopf S, Musahl V, Tashman S, Szczodry M, Shen W, Fu FH. A systematic review of the femoral origin and tibial insertion morphology of the $A C L$. Knee Surg Sports Traumatol Arthrosc. 2009;17:213-219.

8. Zantop T, Petersen W, Sekiya JK, Musahl V, Fu FH. Anterior cruciate ligament anatomy and function relating to anatomical reconstruction. Knee Surg Sports Traumatol Arthrosc. 2006;14:982-992.

9. van Eck CF, Lesniak BP, Schreiber VM, Fu FH. Anatomic single- and double-bundle anterior cruciate ligament reconstruction flowchart. Arthroscopy. 2010;26:258-268
10. Slone HS, Romine SE, Premkumar A, Xerogeanes JW. Quadriceps tendon autograft for anterior cruciate ligament reconstruction: a comprehensive review of current literature and systematic review of clinical results. Arthroscopy. 2015;31:541-554.

11. Rabuck SJ, MusahI V, Fu FH, West RV. Anatomic anterior cruciate ligament reconstruction with quadriceps tendon autograft. Clin Sports Med. 2013;32:155-164.

12. DeAngelis JP, Fulkerson JP. Quadriceps tendon - a reliable alternative for reconstruction of the anterior cruciate ligament. Clin Sports Med. 2007;26:587-596.

13. Lund B, Nielsen T, Faunø P, Christiansen SE, Lind M . Is quadriceps tendon a better graft choice than patellar tendon? A prospective randomized study. Arthroscopy. 2014;30:593-598.

14. Fink C, Herbort M, Abermann E, Hoser C. Minimally invasive harvest of a quadriceps tendon graft with or without a bone block. Arthrosc Tech. 2014;3:e509-e513.

15. Todor A, Caterev S, Nistor DV, Khallouki Y. Free Bone Plug Quadriceps Tendon Harvest and Suspensory Button Attachment for Anterior Cruciate Ligament Reconstruction. Arthrosc Tech. 2016;5:e541-e544.

16. Araujo PH, van Eck CF, Macalena JA, Fu FH. Advances in the three-portal technique for anatomical single- or double-bundle $A C L$ reconstruction. Knee Surg Sports Traumatol Arthrosc. 2011;19:1239-1242.

17. Yasuda K, van Eck CF, Hoshino Y, Fu FH, Tashman S. Anatomic singleand double-bundle anterior cruciate ligament reconstruction, part 1: basic science. Am J Sports Med. 2011;39:1789-1799.

18. Karikis I, Desai N, Sernert N, Rostgard-Christensen L, Kartus J. Comparison of Anatomic Double- and Single-Bundle Techniques for Anterior Cruciate Ligament Reconstruction Using Hamstring Tendon Autografts: A Prospective Randomized Study With 5-Year Clinical and Radiographic Follow-up. Am J Sports Med. 2016;pii:0363546515626543. [Epub ahead of print].

19. Herbort M, Domnick C, Raschke MJ, et al. Comparison of Knee Kinematics After Single-Bundle Anterior Cruciate Ligament Reconstruction via the Medial Portal Technique With a Central Femoral Tunnel and an Eccentric Femoral Tunnel and After Anatomic Double-Bundle Reconstruction: A Human Cadaveric Study. Am J Sports Med. 2016;44:126-132.

20. Hussein M, van Eck CF, Cretnik A, Dinevski D, Fu FH. Prospective randomized clinical evaluation of conventional single-bundle, anatomic single-bundle, and anatomic double-bundle anterior cruciate ligament reconstruction: 281 cases with 3- to 5-year follow-up. Am J Sports Med. 2012;40:512-520. 